\title{
A EDUCAÇÃO DE CRIANÇAS E ADOLESCENTES COM DEFICIÊNCIA NO CONTEXTO DAS POLÍTICAS SOCIAIS
}

\author{
Education of disabled children and adolescents in the social policies context
}

\author{
La educación de niños y adolescentes con discapacidad en el contexto de las \\ políticas sociales
}

\author{
Regina Célia Passos Ribeiro de Campos* \\ Michele Aparecida de Sá** \\ Ana Célia Passos Pereira Campos***
}

\begin{abstract}
Resumo
A história da educação das pessoas com deficiência no Brasil foi marcada pela ausência de iniciativas do Estado. Desse modo, o objetivo deste estudo foi discutir o direito à educação escolar dos alunos com deficiência a partir da reflexão sobre as políticas educacionais no contexto das políticas sociais. As principais fontes documentais analisadas foram aquelas que formalizam e instituem as diretrizes para a Educação Especial na perspectiva da educação inclusiva. Também foram utilizados os dados do Censo Escolar da Educação Básica disponibilizados pelo Instituto Nacional de Estudos e Pesquisas Educacionais Anísio Teixeira (INEP). O estudo permitiu perceber que os direitos são constituídos a partir de lutas históricas e demandas por novos direitos. Entre as garantias legais para as pessoas com deficiência está a inclusão escolar. Os avanços dessa inclusão são legítimos como podemos observar nos dados do censo escolar da Educação Básica, mas precisamos dialogar e participar politicamente para que as políticas educacionais brasileiras não estejam marcadas ou se baseiem em legislações educacionais difusas, impessoais e internacionalizadas que, na maioria das vezes, não levam em conta a diversidade e a complexidade da realidade do ensino brasileiro.
\end{abstract}

PALAVRAS-CHAVE: Educação Especial. Público-alvo da Educação Especial. Políticas sociais.

\footnotetext{
* Doutora em Educação. Professora do Departamento de Ciências Aplicadas à Educação da Faculdade de Educação da Universidade Federal de Minas Gerais (UFMG). Endereço postal: Av. Pres. Antônio Carlos, 6627 - Pampulha, Belo Horizonte - MG, 31270-901 - FaE/DECAE - gabinete 1604. Telefone: 34095326. E-mail: geine.ufmg@ @mail.com Orcid: https://orcid.org/0000-0003-2089-4702

** Doutora em Educação Especial pela Universidade Federal de São Carlos (UFSCAR). Professora do Departamento de Ciências Aplicadas à Educação da Faculdade de Educação da Universidade Federal de Minas Gerais (UFMG). Endereço postal: Av. Pres. Antônio Carlos, 6627 - Pampulha, Belo Horizonte MG, 31270-901 - FaE/DECAE - gabinete 1604. E-mail: micheledesa20@hotmail.com Orcid: https://orcid.org/0000-0001-8076-8383

*** Bacharel em Direito pela Faculdade de Direito da Universidade Federal de Minas Gerais (FD/UFMG). Mestranda em Direito pela Pontifícia Universidade Católica de Minas Gerais - PUC Minas. Endereço postal: Av. Pres. Antônio Carlos, 6627 - Pampulha, Belo Horizonte - MG, 31270-901 - FaE/DECAE gabinete 4604. E-mail: anacelila.ufmg @ gmail.com
} 


\begin{abstract}
The history of disabled people's education in Brazil was marked by the absence of State initiatives. Therefore, this study aimed at discussing the right to school education of disabled students from the reflection about educational policies in the social policies context. The main analyzed documental sources were those that formalize and institute the Special Education Guidelines under the inclusive educational perspective. Data from the Basic Schooling Census supplied by the National Institute of Educational Studies and Research Anísio Teixeira (INEP) were also used. The study allowed us to note that the rights are constituted from the historical fights and demands for new rights. Among the legal guarantees for disabled people is the educational inclusion. The advances of this inclusion are legitimate as we can observe in the Basic Schooling Census, but there is a need to dialog and participate politically so that the Brazilian educational policies are not marked or based on diffuse educational legislations, impersonal and internationalized, which, in their majority, do not consider the diversity and complexity of the Brazilian education reality.
\end{abstract}

KEYWORDS: Special Education. Target Public of Special Education. Social Policies.

\title{
Resumen
}

La historia de la educación para personas con discapacidad en Brasil ha estado marcada por la ausencia de iniciativas estatales. Por lo tanto, el objetivo de este estudio se centra en discutir el derecho a la educación escolar para estudiantes con discapacidades basado en la reflexión sobre políticas educativas en el contexto de las políticas sociales. Las principales fuentes documentales analizadas han sido aquellas que formalizan e instituyen las pautas para la Educación Especial desde la perspectiva de la educación inclusiva. También se han utilizado datos del Censo de Escuelas de Educación Básica proporcionado por el Instituto Nacional de Estudios e Investigación Educativa (INEP) Anísio Teixeira. El estudio nos ha permitido percatarnos de que los derechos están constituidos por las luchas históricas y las demandas de nuevos derechos. Entre las garantías legales para las personas con discapacidad está la inclusión escolar. Los avances de esta inclusión son legítimos como podemos ver en los datos del censo escolar de Educación Básica, pero necesitamos dialogar y participar políticamente para que las políticas educativas brasileñas no estén marcadas o se basen en una legislación educativa difusa, impersonal e internacionalizada que, en la mayoría de los casos, no tengan en cuenta la diversidad y complejidad de la realidad de la educación brasileña.

PALABRAS CLAVE: Educación Especial. Público objetivo de Educación Especial. Políticas sociales.

\section{INTRODUÇÃO}

O presente estudo apresenta uma discussão sobre o direito à educação escolar do público-alvo da Educação Especial, a partir da reflexão sobre as políticas de educação inclusiva para as pessoas com deficiência no panorama das políticas sociais brasileiras.

Compreendemos políticas sociais como ações que determinam o padrão de proteção social implementado pelo Estado, voltadas para a redistribuição dos benefícios sociais. São políticas estas que almejam a diminuição das desigualdades produzidas pelo desenvolvimento socioeconômico (HÖFLING, 2001).

Entendemos que a política social é uma modalidade de políticas públicas, que são compreendidas, segundo Höfling (2001, p. 31), como o "Estado em ação", ou seja, 
políticas públicas de acordo com a autora são "[...] as de responsabilidade do Estado quanto à implementação e manutenção a partir de um processo de tomada de decisões que envolve órgãos públicos e diferentes organismos e agentes da sociedade relacionados à política implementada." A partir deste contexto, entendemos a educação das pessoas com deficiência como uma política pública de corte social e de responsabilidade do Estado brasileiro.

Podemos situar a Declaração Universal dos Direitos Humanos de 1948 como marco decisivo na mudança do paradigma de segregação para um paradigma integracionista na abordagem educacional das pessoas com deficiência. Em decorrência da devastação dos países causada pela $2^{\mathrm{a}}$ Guerra Mundial e do grande número de pessoas amputadas ou marcadas mentalmente pelos horrores da guerra, os governos começaram a se preocupar em garantir o direito à Vida, à Paz e a outros direitos fundamentais, entre eles, à Educação.

Como reflexo dessa dinâmica, a Declaração Universal dos Direitos Humanos, em seu artigo 26, postula o direito de todo homem à instrução gratuita e orientada ao desenvolvimento da personalidade, à promoção da tolerância e da paz.

A segunda metade do século XX, portanto, abre-se para a era das políticas públicas e sociais em vários países, inclusive no Brasil. Positivou-se o Direito à Educação assegurando o acesso à escola pública comum às pessoas com deficiência. Não há dúvidas do avanço dessa normatização, pois baseado nela que outras normas se sucederam.

No cenário brasileiro, segundo Angelini Neta (2005), o Direito Fundamental à Educação está garantido como Direito Humano Fundamental na Constituição da República de 1988. Isso significa dizer que, como a dignidade da pessoa humana é "fim último de toda e qualquer ciência", os Direitos Humanos são constituídos de um "conjunto de condições mínimas necessárias para que a vida humana seja digna", logo, entenderemos que o Direito Humano à Educação se torna "elo de ligação entre o homem e o seu desenvolvimento sociocultural".

No que tange à educação das pessoas com deficiência, somente na década de 1970, a Educação Especial passou a fazer parte oficialmente da pauta de assuntos governamentais brasileiros, com a criação de órgãos específicos no Ministério da Educação. Por um longo período, com base no paradigma integracionista, as crianças e jovens com deficiência foram educadas nas escolas especiais que eram substitutivas da educação comum e apresentava uma proposta de educação diferenciada, individualizada, especializada e voltada para, entre outras atividades, as atividades da vida diária.

Nas últimas décadas do século XX, por uma série de medidas normativas do processo de redemocratização do país, foi sendo forjado um novo paradigma, o paradigma inclusivo. Hoje, a inclusão escolar é uma demanda do sistema educacional brasileiro, o que significa que as crianças e jovens com deficiência, Transtornos do Espectro do Autismo (TEA) e com Altas Habilidades/Superdotação têm o direito de frequentar livremente as escolas comuns, cabendo a estas instituições de ensino da rede pública e privada fornecerem os apoios necessários para que o processo de ensino e aprendizagem aconteça.

A partir do contexto apresentado, o presente estudo tem como objetivo discutir o direito à educação escolar dos alunos com deficiência a partir da reflexão sobre as políticas educacionais no contexto das políticas sociais brasileiras. As principais fontes 
documentais analisadas neste estudo foram aquelas que formalizam e instituem as Diretrizes para a Educação Especial na perspectiva da educação inclusiva e, os dados do Censo Escolar da Educação Básica, coletados e divulgados pelo Instituto Nacional de Estudos e Pesquisas Educacionais Anísio Teixeira (INEP).

\title{
A garantia constitucional da Educação Especial no Brasil
}

A legislação brasileira em vigor tem se pautado em Tratados e Convenções Internacionais para abordar as garantias das pessoas com deficiências, a fim de assegurar o acesso irrestrito destes aos seus direitos civis e de cidadania. Nesse ponto, vale ressaltar que, as normas de Direito Internacional implicam em uma estreita relação com o Direito Interno. Isso acontece na medida em que cada Estado signatário se vincula obrigatoriamente ao acordado, obrigando os seus poderes internos a implementarem a matéria aderida sob pena de uma responsabilização internacional.

Ao observar o cenário político em torno da elaboração das normas regulamentadoras da educação inclusiva, percebe-se essencialmente a absorção de preceitos internacionais a direcionar as discussões e práticas internas no Brasil. Para garantir as concepções já definidas fora do país, as estratégias nacionais buscam manter certa coerência nas decisões políticas.

Como afirmam Glat e Pletsch (2012, p. 20):

\begin{abstract}
A consagração da política de educação inclusiva, por diversas conferências internacionais e documentos firmados no decorrer da década de 1990, fundamentou ações com a intenção de garantir que todos os alunos, sem distinção, pudessem ter acesso, permanência e aprendizagem na escola. Nesse cenário, foi estabelecido um pacto que mobilizou vários governos, entre eles o Brasil, para a implantação de reformas significativas em seus sistemas de ensino, a fim de acatar as metas propostas para uma educação para todos. (...) Não se pode ignorar, porém, que a política de educação inclusiva se insere num contexto mais amplo, com implicações de natureza estrutural, nem sempre aparente nas diretrizes oficiais.
\end{abstract}

Alguns documentos internacionais implicam diretamente ou indiretamente em mudanças na política educacional brasileira. Quando, assinados pelo Brasil, os acordos fixam diretrizes para o Direito Interno do país se adequar às demandas neles elencadas. Percebemos essa adequação em diversos dispositivos: Constituição Federal (1988), Estatuto da Criança e do Adolescente (ECA/1990), Lei de Diretrizes e Bases da Educação Nacional (LDB/1996), Política Nacional de Educação Especial na perspectiva da Educação Inclusiva (PNEE/2008), Plano Nacional de Educação (PNE/2014-2024), legislações específicas e políticas públicas diferenciadas.

Fica evidente, por exemplo, a congruência do artigo 205 da Constituição Federal de 1988 com o artigo 26 da Declaração dos Direitos Humanos de 1948, no uso do termo "todos" como destinatário da norma e no traçar do objetivo do pleno desenvolvimento da pessoa (ou da personalidade humana como quer a Declaração). Também o artigo 206 da Constituição Federal estabelece como princípio que o ensino será ministrado pela igualdade de condições, liberdade de aprender, pluralismo de ideias, gratuidade do ensino público e valorização dos profissionais do ensino, entre outros.

É a Constituição Brasileira que garante o pluralismo de ideias e concepções pedagógicas que rompem com as práticas hegemônicas e garantem o diálogo e a 
liberdade de expressão. A partir da promulgação da atual Constituição, os preceitos que garantem os direitos das pessoas com deficiência são reeditados, aprofundando e operacionalizando essas garantias.

Ao realizarmos uma breve investigação sobre textos jurídicos referentes à educação, o tema específico dos direitos das pessoas com deficiência aparece, direta ou indiretamente, nos seguintes textos, entre outros: Convenção de Viena (1969 - Direito dos Tratados); Constituição Federal (1988); Declaração Mundial sobre Educação para Todos (1990); Estatuto da Criança e do Adolescente (1990); Declaração de Nova Delhi (1993); Declaração de Salamanca (1994), Declaração Internacional de Montreal sobre inclusão (2001). No Brasil, além da Constituição Federal de 1988, a LDB/1996, o PNE (2014-2024), Lei $\mathrm{n}^{\mathbf{o}}$ 10.436/2002 (Língua Brasileira de Sinais Libras) - 2002, PNEE/2008 e o Decreto $n^{\circ}$ 7.611/2011 e a Lei 13.146/15 - Lei Brasileira de Inclusão (2015).

Considerando que atualmente a perspectiva neoliberal domina grande parte dos países ocidentais e se apresenta nas medidas de reestruturação capitalista dos países, internacionalização e globalização da economia, podemos vislumbrar sua concretização na ênfase das relações de mercado como reguladoras da vida social. Em contrapartida, nosso desafio é manter a gestão democrática das políticas sociais, cujo esforço se expressa desde a Constituição da República de 1988 e cujos dispositivos são reafirmados por uma série de normatizações e reformas administrativa, entre elas a Lei de Diretrizes e Bases da Educação Brasileira (LDB/1996), que vão se consolidar no atual Plano Nacional de Educação (2014-2024) e na atual Lei Brasileira de Inclusão da Pessoa com Deficiência (Estatuto da Pessoa com Deficiência - Lei 13.146 /15).

Em 2015, o Estatuto da Pessoa com Deficiência (EPD) altera parte do Código Civil e do Código de Processo Civil Brasileiro, embasada pela Convenção de Nova York. Ele desconstrói o conceito de capacidade legal, retirando a deficiência como fundamento da incapacidade. Ainda que necessitando de um curador, a pessoa com deficiência será considerada capaz para os atos da vida civil, sendo reconhecida sua autodeterminação. Trata-se de significativo avanço porquanto retira o rótulo da incapacidade para a deficiência.

Destaca-se, ainda, a obrigatoriedade das instituições públicas e privadas em receber as pessoas com deficiência, imposta pelo EPD. Logo que foi sancionada, em julho de 2015, houve uma ampla discussão social acerca da possibilidade de cobrança de taxas extras nas escolas particulares para os alunos com deficiência, ou ainda, um reajuste para todas as mensalidades para cobrir os custos do acolhimento destes alunos.

A lei entrou em vigor em janeiro de 2016, concedendo prazo para adaptação das instituições de ensino. Nesse período, a Confederação Nacional dos Estabelecimentos de Ensino (CONFENEN) ajuizou Ação Direta de Inconstitucionalidade (ADI n. 5357) visando retirar a obrigação das escolas particulares de se adaptarem e pleiteando o aumento do valor das mensalidades e matrículas para receber os estudantes com deficiência. Entre os argumentos estavam o "alto custo econômico" e o dever do Estado no atendimento educacional as pessoas com deficiência.

A ação foi julgada improcedente no Supremo Tribunal Federal, ou seja, foi reconhecido que as escolas, públicas ou privadas, exercem uma função social ao cumprir o dever de inclusão, não podendo cobrar taxas extras por isso. É reconhecido também o direito das pessoas com deficiência em escolher onde pretende estudar, enfatizando a sua capacidade de autodeterminação. 
Como podemos observar nos últimos anos ocorreu uma ampliação das políticas sociais destinadas às pessoas com deficiência, especificamente as direcionadas à educação. A partir desta realidade, apresentaremos a seguir como as políticas destinadas a educação inclusiva influenciaram no acesso e permanência dos alunos público-alvo da Educação Especial ${ }^{1}$ à Educação Básica.

\section{Das políticas educacionais inclusivas ao acesso à educação básica}

Para investigarmos a situação do acesso e permanência dos alunos público-alvo da educação especial à Educação Básica, aderimos como fonte às estatísticas públicas do Censo da Educação Básica, coletadas e divulgadas pelo Instituto Nacional de Estudos e Pesquisas Educacionais Anísio Teixeira (INEP). De acordo com o INEP ${ }^{2}$, as informações coletadas são usadas como subsídio para o planejamento e definição das políticas educacionais desenvolvidas pelo Ministério da Educação (MEC), para repasse dos recursos destinados às escolas públicas e, também, para acompanhamento das metas do Plano Nacional de Educação.

Para este estudo, utilizamos os dados do censo escolar, especificamente as sinopses, referentes ao período de 2010 a 2019. Escolhemos este recorte temporal porque a intenção foi verificar como as políticas educacionais de cunho inclusivo democratizaram o acesso e permanência dos alunos com deficiência nesta última década. Para esta análise, utilizamos dados de matrículas de alunos público-alvo da Educação Especial, em escolas de ensino regular e escolas de Educação Especial e/ou classes especiais substitutiva, para analisar o acesso. Para verificar a questão da permanência, foram utilizados dados sobre infraestrutura referentes especificamente a existência de salas para o Atendimento Especializado e acessibilidade dentro das escolas.

A primeira figura apresenta o total de matrículas de alunos público-alvo da Educação Especial na Educação Básica, no período de 2010 a 2019.

Figura 1. Matrículas de alunos público-alvo da Educação Especial na Educação Básica

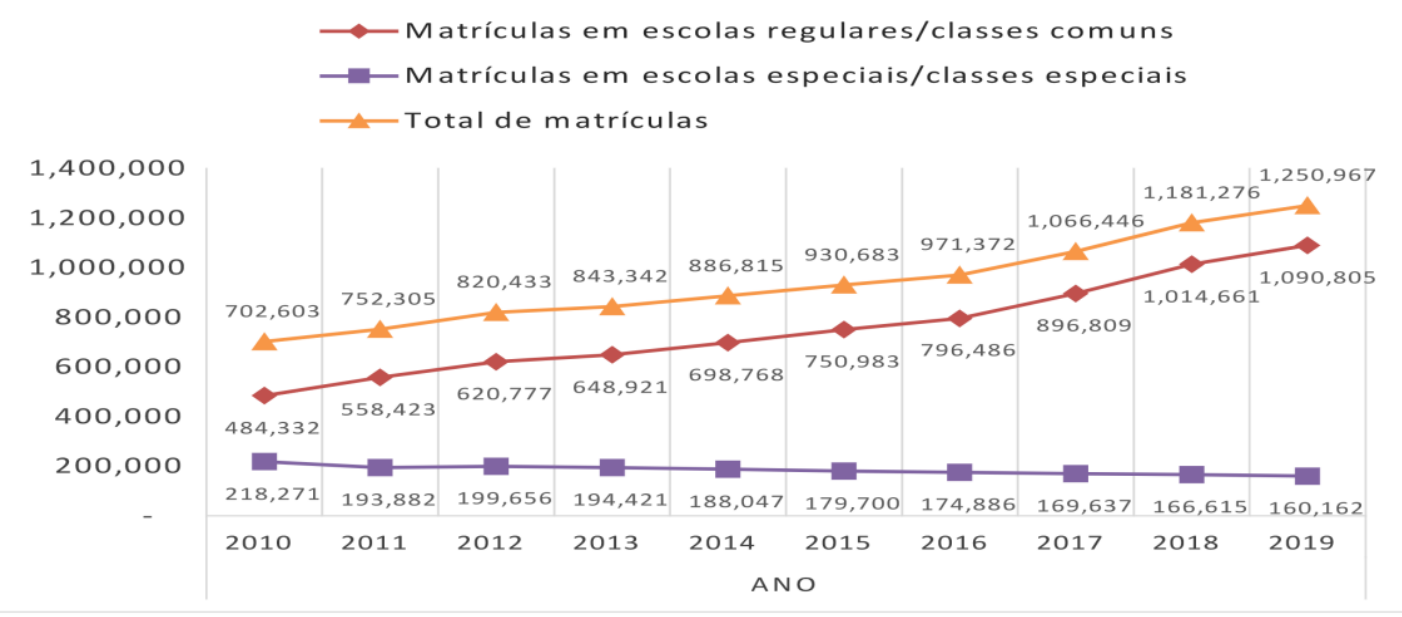

\footnotetext{
${ }^{1}$ Considera-se público-alvo da Educação Especial os alunos com deficiência, alunos com transtornos globais do desenvolvimento e alunos com altas habilidades/superdotação. (BRASIL, 2008)

Informações coletadas na página do <http://portal.mec.gov.br/component/tags/tag/32124?start=20>.
} 
Fonte: Elaboração própria, com base no Censo da Educação Básica - INEP (BRASIL, 2010; 2011; 2012; 2013; 2014; 2015; 2016; 2017; 2018; 2019).

De acordo com os dados apresentados, verifica-se que no período estudado teve um aumento expressivo de matrículas de alunos público-alvo da Educação Especial na Educação Básica. O cotejamento dos dados de 2019 com os de 2010 mostra um aumento de $78,04 \%$ do número de matrículas de alunos público-alvo da Educação Especial.

Ao analisar separadamente os dados de matrículas em escolas regulares/classes comuns e escolas especiais e/ou classes especiais (ensino substitutivo), verificou-se que no caso das matrículas de alunos público-alvo da educação especial em escolas regulares/classes comuns teve um aumento de 125,2\% quando comparado o ano de 2010 a 2019. Com relação às matrículas em escolas especiais e/ou classe especial, percebe-se, ao cotejar os dados de 2019 com os de 2010 um decréscimo das matrículas. No período analisado houve redução de $26,6 \%$. Apesar dessa redução, não podemos desconsiderar que mais de 160 mil alunos ainda permanecem em espaços segregados de ensino.

A partir dos dados apresentados na figura 1 percebemos que as políticas públicas com foco na educação inclusiva (BRASIL, 1988; BRASIL, 1996; BRASIL, 2008; BRASIL, 2015) favoreceram o acesso dos alunos com deficiência à Educação Básica, especificamente em escolas regulares/classes comuns. Seguindo a tendência das políticas inclusivas, que asseguram o acesso preferencialmente na rede regular de ensino, ocorreu uma redução das matrículas nas escolas especiais e/ou classes especiais, porém ainda tivemos no ano de 2019, 160.162 alunos matriculados em espaços segregados de ensino, fato este que vai à contramão das políticas de educação na perspectiva inclusiva.

Na figura 2 são apresentados os dados referentes às matrículas dos alunos público-alvo da Educação Especial nas redes públicas e privadas de ensino.

Figura 2. Matrículas de alunos público-alvo da Educação Especial nas redes pública e privada.

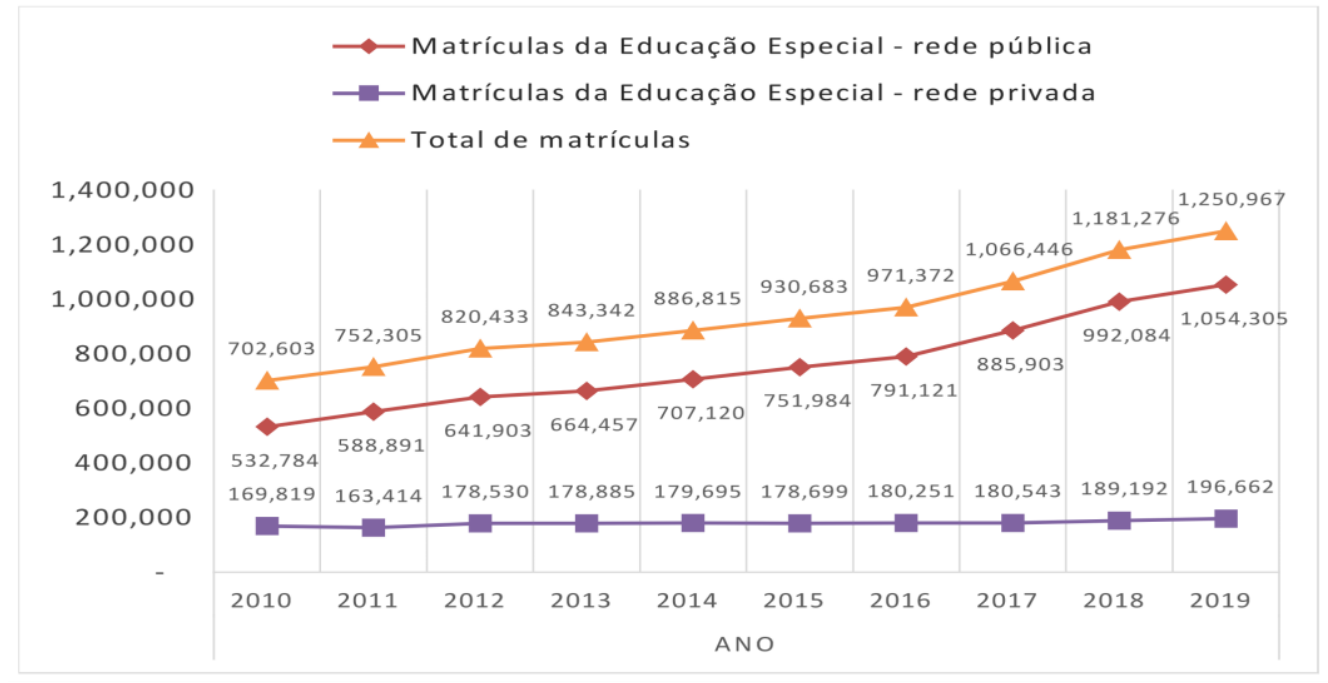

Fonte: Elaboração própria, com base no Censo da Educação Básica - INEP (BRASIL, 2010; 2011; 2012; 2013; 2014; 2015; 2016; 2017; 2018; 2019). 
Os dados apresentados na figura 2 mostram que as matrículas de alunos públicoalvo da Educação Especial aumentaram, no decorrer do período analisado, tanto nas escolas da rede pública quanto nas escolas da rede privada. Ao analisar separadamente as duas redes ensino, constatou-se que na rede pública teve um aumento de 97,9\% quando cotejados os dados do ano de 2019 com o de 2010. No caso da rede privada também ocorreu um aumento de $15,8 \%$ no período analisado.

Ao comparar os dados do ano de 2019 das matrículas da rede pública e privada, verificou-se que 84,3\% das matrículas dos alunos público-alvo da Educação Especial estavam na rede pública de ensino. Este fato pode estar relacionado às políticas sociais implementadas nas últimas décadas que fizeram com que o Estado assumisse a educação deste público como sendo de sua responsabilidade.

A partir dos dados apresentados anteriormente, percebe-se que o acesso das pessoas com deficiência à Educação Básica aumentou expressivamente na última década, porém cabe investigarmos como as redes de ensino estão se organizando para garantir a permanência destes alunos nas escolas. Neste estudo, apresentaremos dados sobre espaços/salas para o atendimento especializado e acessibilidade nas dependências escolares como fatores que favorecem a permanência dos alunos público-alvo da Educação Especial na Educação Básica.

A tabela 1 mostra dados de escolas que apresentam dependências acessíveis às pessoas com deficiência.

Tabela 1. Escolas com dependências acessíveis às pessoas com deficiência

\begin{tabular}{|l|c|c|c|}
\hline \multirow{2}{*}{ ANO } & \multicolumn{2}{|c|}{ Escolas } & \multirow{2}{*}{} \\
\cline { 2 - 3 } & Rede pública & Rede privada & TOTAL \\
\hline $\mathbf{2 0 1 0}$ & 19.022 & 8.926 & 27.948 \\
\hline $\mathbf{2 0 1 1}$ & 23.297 & 10.262 & 33.559 \\
\hline $\mathbf{2 0 1 2}$ & 27.247 & 11.406 & 38.653 \\
\hline $\mathbf{2 0 1 3}$ & 29.376 & 12.226 & 41.602 \\
\hline $\mathbf{2 0 1 4}$ & 31.311 & 13.142 & 44.453 \\
\hline $\mathbf{2 0 1 5}$ & 34.872 & 12.410 & 47.282 \\
\hline $\mathbf{2 0 1 6}$ & 37.593 & 13.354 & 50.947 \\
\hline $\mathbf{2 0 1 7}$ & 39.003 & 14.882 & 53.885 \\
\hline $\mathbf{2 0 1 8}$ & 39.850 & 16.049 & 55.899 \\
\hline
\end{tabular}

Fonte: Elaboração própria, com base no Censo da Educação Básica - INEP (BRASIL, 2010; $2011 ; 2012 ; 2013 ; 2014 ; 2015 ; 2016 ; 2017$ 2018).

De acordo com os dados da tabela 1, constata-se que no período analisado o número de escolas públicas e privadas com dependências acessíveis às pessoas com deficiência aumentou. Ao cotejar os dados de 2018 com os de 2010 percebemos um aumento de mais $100 \%$. Entretanto, ao comparar estes dados ao número total de escolas existentes no Brasil, no ano de 2018, verificou-se que apenas $31 \%$ das escolas da Educação Básica possuíam dependências acessíveis às pessoas com deficiência.

Ao analisar separadamente os dados das escolas das redes pública e privada, identificamos que no ano de 2018 28\% das escolas públicas possuíam dependências acessíveis às pessoas com deficiência e, no caso da rede privada, apenas $39 \%$ das 
escolas eram acessíveis.

Com relação à existência de salas para o Atendimento Educacional Especializado, nas dependências das escolas, os dados serão apresentados na tabela a seguir:

Tabela 2. Sala para o Atendimento Especial

\begin{tabular}{|c|c|c|c|}
\hline \multirow{2}{*}{ ANO } & \multicolumn{2}{|c|}{ Escolas } & \multirow{2}{*}{} \\
\cline { 2 - 3 } & Rede pública & Rede privada & TOTAL \\
\hline $\mathbf{2 0 1 0}$ & 10.245 & 1.973 & 12.218 \\
\hline $\mathbf{2 0 1 1}$ & 14.224 & 1.865 & 16.089 \\
\hline $\mathbf{2 0 1 2}$ & 19.208 & 1.869 & 21.077 \\
\hline $\mathbf{2 0 1 3}$ & 21.652 & 1.968 & 23.620 \\
\hline $\mathbf{2 0 1 4}$ & 24.315 & 2.001 & 26.316 \\
\hline $\mathbf{2 0 1 5}$ & 28.030 & 1.925 & 29.955 \\
\hline $\mathbf{2 0 1 6}$ & 29.822 & 2.292 & 32.114 \\
\hline $\mathbf{2 0 1 7}$ & 31.673 & 2.861 & 34.534 \\
\hline $\mathbf{2 0 1 8}$ & 31.766 & 2.833 & 34.599 \\
\hline
\end{tabular}

Fonte: Elaboração própria, com base no Censo da Educação Básica - INEP (BRASIL, 2010; $2011 ; 2012 ; 2013 ; 2014 ; 2015 ; 2016 ; 2017$ 2018).

Os dados apresentados na tabela 2 mostram que no período analisado teve um aumento expressivo de salas para o atendimento especial. Ao comparar os dados do ano de 2010 com os de 2019 verificou-se um aumento de $183 \%$ de salas para o atendimento especial em escolas das redes pública e privada. Ao analisar os dados separadamente identificamos que no ano de 2018, 22\% das escolas públicas tinham salas para atendimento especial. No caso da rede privada, neste mesmo ano, apenas $7 \%$ das escolas possuíam em suas dependências esse tipo de sala.

Apesar de ocorrer aumento do número de salas para atendimento especial no período analisado, verifica-se que temos um número reduzido deste tipo de espaço nas escolas. Quando somamos os dados das escolas públicas e privadas identificamos que no ano de 2018 apenas 19\% das escolas brasileiras possuíam salas para o atendimento especial, número reduzido para atender a demanda de alunos que fazem parte do público-alvo da Educação Especial e tem como garantia legal o direito ao Atendimento Educacional Especializado (BRASIL, 1988; 1996; 2008; 2015).

A partir da análise dos dados, verificou-se ampliação significativa do acesso desses alunos às escolas da Educação Básica, esse movimento pode ter ocorrido por causa das políticas públicas e sociais que foram implementadas no decorrer das duas últimas décadas que democratizaram o acesso à educação dos alunos público-alvo da Educação Especial. Entretanto, pesquisa realizada por Laplane (2015, p. 15), revela que estudos desenvolvidos por pesquisadores da área da Educação Especial apontam para a permanência de problemas que envolvem desde "[...] condições de trabalho de docentes e de escolarização dos alunos, os currículos, a formação docente, as formas de organização do trabalho escolar às condições de acessibilidade física e ao conhecimento".

A aplicação das políticas sociais destinadas à educação inclusivas nas escolas brasileiras, a curto, médio e longo prazos, ocasionam mudanças no estatuto, na estrutura e as práticas pedagógicas que precisam ser discutidas. 


\section{Das políticas inclusivas brasileiras às práticas escolares nas turmas inclusivas das escolas}

O processo de inclusão escolar da criança e do jovem com características do público-alvo da educação especial tem provocado mudanças na dinâmica das escolas. Quando se pensa em termos da política pública, a melhoria da qualidade de ensino das escolas brasileiras, a descentralização dos recursos e a autonomia dada aos professores representam avanços significativos.

No que se refere à organização da escola para o processo de inclusão escolar, é importante que sejam definidos politicamente o sistema de incentivo para as escolas com o provimento do Atendimento Educacional Especializado e recursos didáticopedagógicos adicionais para a flexibilização e o enriquecimento curricular. Torna-se fundamental o Estado investir na garantia de suporte humano, técnico e financeiro para a formação docente inicial e continuada, tornando cada escola uma unidade de capacitação para a equipe escolar.

A criação de um sistema de informações de acesso simples e prático para que o professor possa se expressar e ser escutado, de forma a contar com o apoio de técnicos e especialistas e a adoção de um sistema de centros de apoio regionais com equipe interdisciplinar, poderia fornecer um acompanhamento pontual aos professores e abrir espaço para iniciativas e discussões com a comunidade.

Dentro da escola, a presença da criança ou jovem com deficiência na sala de aula comum deve ser considerada, antes de tudo, como a presença de qualquer aluno, ou seja, antes de tudo é uma criança ou jovem (aluno da escola). Essencialmente, as mudanças inclusivas são mudanças nas concepções sobre a deficiência e as formas de lidar pedagogicamente com ela em termos de oferecer condições de aprendizagem - a acessibilidade estrutural, comunicacional e atitudinal.

A visão inclusiva do processo de ensino e aprendizagem está colocada nos mediadores do processo. Isso significa que a gestão educacional precisa fornecer os recursos e adaptações necessários para promover situações de aprendizagem com equidade para todas as crianças. Trata-se de prover com elementos básicos de comunicação (como por exemplo no caso da surdez, um intérprete) ou elementos estruturais (uma mesa especial para uma criança na cadeira de rodas ou elementos de Comunicação Alternativa para crianças com Transtorno do Espectro Autista (TEA) ou paralisia cerebral) até a organização da sala em pequenos grupos ou duplas, ou a preferência por pesquisas com elementos concretos como maquetes, massa de modelar, recortes, pintura, mesmo nos níveis mais avançados do ensino. Além disso, a flexibilização de tempos, espaços e métodos contribuirá para se pensar novas propostas pedagógicas e formas de avaliação.

Há, essencialmente garantido como direito ao público-alvo da educação especial, o Atendimento Educacional Especializado (AEE) que acontece no contraturno, sendo considerado um espaço de apoio no qual, em trabalho colaborativo, o professor especializado e o professor regente da sala inclusiva traçam juntos um Plano Educacional Individualizado para definir as metodologias, estratégias e suportes necessários para que o aluno possa acompanhar a aula na turma comum.

A efetivação do direito a educação das pessoas com deficiência tem sido um desafio até os dias atuais, porque demanda custos e mudanças nas concepções limitadoras sobre a deficiência, na gestão educacional e na prática docente. 
Essencialmente, as práticas inclusivas fazem emergir questões importantes no que se refere ao esforço de sua implementação, visto as limitações concretas e as urgências da escola brasileira, tais como: a formação e valorização dos professores, a instalação do processo de Atendimento Educacional Especializado, a acessibilidade estrutural, comunicacional e atitudinal das escolas de forma a oferecer os apoios, suportes e recursos pedagógicos que, de fato, potencializem a aprendizagem, entre outros.

Segundo Denari (2008, p. 32) as dificuldades geram obstáculos e retrocessos aos processos inclusivos:

[...] quando, erroneamente, se tem tentado responder por via da racionalidade técnica à diversidade humana. Tal diversidade é vista como um problema que complica os processos de ensino e aprendizagem e não como uma característica própria da e integrada nas experiências cotidianas das pessoas. Cabe lembrar que tal entendimento representa, tipicamente, uma educação homogenizadora e centrada na criação de um aluno em condição de deficiência.

A autora nos permite compreender que romper com a concepção ideológica homogenizadora tradicionalmente implícita nas práticas escolares tradicionais e no exercício de uma educação que mantém a situação de dependência/deficiência requer uma difícil mudança em diferentes níveis. Primeiro, no nível das políticas públicas e sociais, cujas garantias dos direitos adquiridos representam avanços significativos da dimensão político-educativa. Em segundo lugar, as práticas pedagógicas e sua dimensão epistemológica, pois partir da ótica da diversidade requer revisão de paradigmas em que "A educação na e para a diversidade implica, antes, uma mudança epistemológica, na qual a visão tradicional do conhecimento, da relação entre sujeito-objeto e a aprendizagem seja (re) considerada, (re) significada" (DENARI, 2008, p.37). Em terceiro plano, a gestão educacional que, por conter certa dose de autonomia, pode ser criativa e "redesenhar os contextos laborais" produzindo projetos mais colaborativos e participativos, contemplando a formação de seu quadro de funcionários e a captação de recursos e tecnologias necessários. Em quarto plano, a cultura escolar que imprime as formas de ação sobre as questões cotidianas ligadas ao processo de inclusão escolar. E, por fim, mas não menos importante, as práticas pedagógicas inovadoras e inclusivas que representam o repertório de ações pedagógicas que eliminam barreiras e fornecem os recursos técnicos e/ou apoios necessários para que aconteça a participação da criança e do jovem em situação de equidade.

É uma proposta que convoca os gestores a ampliar os muros da escola para estabelecer parcerias interssetoriais e buscar apoio na comunidade e em outras instituições e também desloca o professor do lugar comum e cômodo da aula tradicional, para propostas de aulas mais criativas, dinâmicas, onde todas as crianças ou jovens, cada um com sua diferença, possam participar e contribuir dentro de suas capacidades e potencialidades.

\section{CONSIDERAÇÕES FINAIS}

As reflexões apresentadas buscaram contribuir para clarear elementos que se encontram na fronteira entre os campos de conhecimento do Direito e da Educação. Pretenderam, ainda, abrir um debate, no panorama das políticas públicas e sociais, no que tange especificamente ao direito à educação e sua relação entre as garantias legais definidas pela legislação nacional sobre a inclusão escolar e a prática educacional nas 
escolas brasileiras, evidenciando que as decisões na política educacional brasileira precisam ser contextualizadas a partir das exigências internacionais e do Direito Constitucional à Educação. Essa dinâmica se vincula ao Estado Brasileiro e garante que o desenvolvimento da perspectiva inclusiva nas políticas de Educação Especial não seja barrado por ações governistas, avalizando assim a implementação das medidas tanto almejadas.

Os direitos são constituídos a partir de lutas históricas e demandas por novos direitos. São eles instrumentos de manutenção do status quo social, só podem se constituir e se atualizar na medida em que são reivindicados. Entre as garantias legais para as pessoas com deficiência está a inclusão escolar. Os avanços dessa inclusão são legítimos, mas precisamos dialogar e participar politicamente para que as políticas educacionais brasileiras não estejam marcadas ou se baseiem em legislações educacionais difusas, impessoais e puramente internacionalizadas que, na maioria das vezes, não levam em conta a diversidade e a complexidade da realidade do ensino brasileiro. As legislações educacionais deverão, pois, serem concebidas como fio condutor para a implementação de políticas públicas e sociais verdadeiramente baseadas nas especificidades do contexto brasileiro.

Para além da escola, é importante destacar a participação política democrática de toda a sociedade brasileira, participação da sociedade civil no Conselho Nacional de Educação e nos Fóruns Nacionais de Educação para que o processo de inclusão escolar seja efetivamente constituído. A participação da sociedade civil e, especialmente, dos professores está garantida pelo princípio constitucional da Gestão Democrática. Sendo um serviço público, a Educação garante a democracia, ou seja, está implicada na noção de participação política, seja ela, nacional ou internacional.

A presença da criança e do jovem com deficiência na escola comum desloca concepções individualistas sobre a deficiência para concepções mais amplas, que evocam solidariedade e inclusão. Se muitas vezes a pessoa com deficiência foi tratada a partir de descrições, classificações, justificativas e orientações, medidas que resultavam em ações segregacionistas ou restritivas, se ocorreram ao longo da história representações e mentalidades que partiam da deficiência e limitações para se criar barreiras, hoje, a inclusão escolar tem sido considerada um processo de mudança social no contexto da Educação, do Trabalho e, em sentido amplo, de toda a sociedade.

Propõe-se, aqui, pensar um enfoque diferente: ver a inclusão escolar como uma questão individual, social e política. Um retorno ao individual, porque urge que as pessoas com deficiência estejam designadas ao centro, no sentido do protagonismo e empoderamento de seu próprio processo de inclusão, como atores de sua aprendizagem. Sem descuidar de analisar das concepções limitantes vigentes em nossa cultura, política e sociedade, é bom também levarem conta que ao lado de uma obrigação legal, há sempre uma questão de ética.

Em consonância com o que foi acordado nos protocolos internacionais e com os preceitos do ordenamento jurídico cabe, portanto, um esforço individual e coletivo, de participação democrática e solidária para criarmos a educação brasileira, conforme diz o professor Bearthou (2009) com uma "mentalidade includente", que inclua incondicional e efetivamente todas as diferenças.

\section{REFERÊNCIAS}


ANGELINI NETA, A. H. O direito à educação como um direito humano fundamental e sua relação com a manutenção/fortalecimento das democracias contemporâneas. In: $3^{\circ}$ Congresso Brasileiro de Direito Internacional, 2005, Curitiba. Estudos de Direito Internacional: anais do $3^{\circ}$ Congresso Brasileiro de Direito Internacional. Curitiba: Juruá Editora, 2005. v. III

BERTHOU, François-Xavier. Mentalidade includente - sociedade inclusiva. São Paulo: Memnon, 2009.

BRASIL. Constituição da República Federativa do Brasil. Brasília: Imprensa Oficial, 1988.

Estatuto da Criança e do Adolescente. Lei 8069 de 13 de julho de 1990. Brasília: Imprensa Oficial, 1990.

, Ministério da Educação. Lei de Diretrizes e Bases da Educação Nacional. Lei n. 9394/96. Brasília: MEC, 1996.

BRASIL. Ministério da Educação. Lei 10.436, de 24 de abril de 2002. Dispõe sobre a língua brasileira de sinais. Brasília, 2002.

Portaria n. 948, de 09 de outubro de 2007. Dispõe sobre Política Nacional de Educação Especial na Perspectiva da Educação Inclusiva. Brasília, DF, 2008.

Ministério da Educação. Instituto Nacional de Estudos e Pesquisas Educacionais Anísio Teixeira - INEP. Censo Escolar da Educação Básica - 2010. Brasília, DF, 2010. Disponível em: <http://portal.inep.gov.br/sinopses-estatisticas-daeducacao-basica>. Acesso em: 20 abril. 2020.

Ministério da Educação. Instituto Nacional de Estudos e Pesquisas Educacionais Anísio Teixeira - INEP. Censo Escolar da Educação Básica - 2011. Brasília, DF, 2011. Disponível em: <http://portal.inep.gov.br/sinopses-estatisticas-daeducacao-basica>. Acesso em: 20 abril. 2020.

Ministério da Educação. Instituto Nacional de Estudos e Pesquisas Educacionais Anísio Teixeira - INEP. Censo Escolar da Educação Básica - 2012. Brasília, DF, 2012. Disponível em: <http://portal.inep.gov.br/sinopses-estatisticas-daeducacao-basica>. Acesso em: 20 abril. 2020.

Ministério da Educação. Instituto Nacional de Estudos e Pesquisas Educacionais Anísio Teixeira - INEP. Censo Escolar da Educação Básica - 2013. Brasília, DF, 2013. Disponível em: <http://portal.inep.gov.br/sinopses-estatisticas-daeducacao-basica>. Acesso em: 20 abril. 2020. 
Ministério da Educação. Instituto Nacional de Estudos e Pesquisas Educacionais Anísio Teixeira - INEP. Censo Escolar da Educação Básica - 2014. Brasília, DF, 2014. Disponível em: <http://portal.inep.gov.br/sinopses-estatisticas-daeducacao-basica>. Acesso em: 20 abril. 2020.

Ministério da Educação. Instituto Nacional de Estudos e Pesquisas Educacionais Anísio Teixeira - INEP. Censo Escolar da Educação Básica - 2015. Brasília, DF, 2015. Disponível em: <http://portal.inep.gov.br/sinopses-estatisticas-daeducacao-basica>. Acesso em: 20 abril. 2020.

Ministério da Educação. Instituto Nacional de Estudos e Pesquisas Educacionais Anísio Teixeira - INEP. Censo Escolar da Educação Básica - 2016. Brasília, DF, 2016. Disponível em: <http://portal.inep.gov.br/sinopses-estatisticas-daeducacao-basica>. Acesso em: 20 abril. 2020.

Ministério da Educação. Instituto Nacional de Estudos e Pesquisas Educacionais Anísio Teixeira - INEP. Censo Escolar da Educação Básica - 2017. Brasília, DF, 2017. Disponível em: <http://portal.inep.gov.br/sinopses-estatisticas-daeducacao-basica>. Acesso em: 20 abril. 2020.

Ministério da Educação. Instituto Nacional de Estudos e Pesquisas Educacionais Anísio Teixeira - INEP. Censo Escolar da Educação Básica - 2018. Brasília, DF, 2018. Disponível em: <http://portal.inep.gov.br/sinopses-estatisticas-daeducacao-basica>. Acesso em: 20 abril. 2020.

Ministério da Educação. Instituto Nacional de Estudos e Pesquisas Educacionais Anísio Teixeira - INEP. Censo Escolar da Educação Básica - 2019. Brasília, DF, 2019. Disponível em: <http://portal.inep.gov.br/sinopses-estatisticas-daeducacao-basica>. Acesso em: 20 abril. 2020.

BRASIL. Lei 13.005, de 25 de junho de 2014. Aprova o Plano Nacional de Educação PNE e dá outras providências. Disponível em: . Acesso em: 10 de abril de 2020.

BRASIL. Lei No13.146 de 6 de julho de 2015. Lei Brasileira de Inclusão da Pessoa com Deficiência. Disponível em: <http://www.planalto.gov.br/ccivil_03/_ato20152018/2015/lei/113146.htm>. Acesso em: 23.ago.2017.

CONFERÊNCIA MUNDIAL DE EDUCAÇÃO PARA TODOS, 1990, Jomtien. Declaração mundial sobre educação para todos: satisfação das necessidades básicas de aprendizagem. Jomtien: Unesco, 1990. 
CONFERÊNCIA MUNDIAL SOBRE NECESSIDADES EDUCACIONAIS ESPECIAIS, 1994, Salamanca. Declaração de Salamanca e linha de ação sobre necessidades educativas especiais. Brasília, DF: Corde, 1994.

DECLARAÇÃO UNIVERSAL DOS DIREITOS HUMANOS, ONU, 1948.

DENARI, Fatima Elisabeth. Dimensões teórico-práticas da educação inclusiva. Em: DECHICHI, C.; SILVA, L. (Orgs.). Inclusão escolar e educação especial: teoria e práticas na diversidade. Uberlândia: Editora da UFU, 2008.

GLAT, Rosana; PLETSCH, Mônica. Inclusão escolar de alunos com necessidades especiais. Rio de Janeiro: EDUERJ, 2012.

HOFLING, Eloisa de Mattos. Estado e políticas (públicas) sociais. Cad. CEDES, Campinas, v. 21, n. 55, p. 30-41, Nov. 2001. Disponível em: $<$ http://www.scielo.br/scielo.php?script=sci_arttext\&pid=S01012622001000300003\&ln $\mathrm{g}=\mathrm{en} \& \mathrm{nrm}=\mathrm{iso}>$. Acesso em 28 Abril 2020.

LAPLANE, Adriana Lia Friszman de. O que os dados do censo escolar revelam sobre as barreiras à inclusão. Educação e Fronteiras On-Line. Dourados, v.5, n.13, p.7-20, maio/ago. 2015. Disponível em:

http://ojs.ufgd.edu.br/index.php/educacao/article/view/3762>. Acesso em: 15 abril 2020.

Recebido: 05/04/2020

Aprovado: 09/06/2020 